\title{
A RBMFC de cara nova
}

The new face of RBMFC

La nueva cara de RBMFC

Nulvio Lermen Junior ${ }^{1 *}$

Caros leitores,

É com grande satisfação que tenho a honra de escrever o editorial da primeira edição da Revista Brasileira de Medicina de Família e Comunidade a ir para impressão sob a gestão da nova diretoria da Sociedade Brasileira de Medicina de Família e Comunidade (SBMFC) para o período de 2012 a 2014.

Esta edição marca o início de grandes mudanças na RBMFC, a começar pela alteração de editor. O Dr. Marcelo Demarzo nos deixa depois de um produtivo período à frente da revista para se dedicar aos seus estudos de Pós-Doutorado no exterior, sendo substituído pelo Dr. Armando Henrique Norman.

O Dr. Armando Henrique Norman é médico graduado pela Universidade Federal do Paraná, com residência em Medicina Geral e Comunitária (antigo nome da especialidade Medicina de Família e Comunidade) pela Pontifícia Universidade Católica do Paraná, mestre em Antropologia Médica pela Universidade de Durham (Reino Unido) e assume o desafio de guiar a RBMFC nesse processo de transformação.

Nos próximos meses, esperamos que vocês gradualmente passem a ter uma nova experiência na leitura da RBMFC, tanto na questão da modernização do processo editorial (o qual buscaremos que seja cada vez mais voltado para as novas mídias eletrônicas, facilitando assim o acesso a todos os nossos leitores que estejam conectados à rede) quanto no que concerne ao conteúdo que passará a ter um foco mais voltado para a atualização clínica do Médico de Família e Comunidade (MFC). Desse modo, a RBMFC tem como principal objetivo ser uma fonte de busca preferencial para o aperfeiçoamento contínuo dos profissionais atuantes na Atenção Primária à Saúde (APS) e nas equipes da Estratégia Saúde da Família (ESF).

Esperamos a contribuição de todos, seja no envio de trabalhos para possível publicação, seja na participação no processo de revisão editorial, ou ainda na simples leitura e envio de comentários visando o aperfeiçoamento do nosso trabalho.

Um grande abraço a todos.

${ }^{1}$ Presidente da Sociedade Brasileira de Medicina de Família e Comunidade. nulvio@hotmail.com

Autor correspondente. 